\title{
The impact of platelet-rich plasma on postoperative outcomes after spinal fusion: a systematic review and meta-analysis
}

\author{
Yagiz Ugur Yolcu, MD, 1,2 Waseem Wahood, MS,1-3 Abdullah T. Eissa, MD,,2 \\ Mohammed Ali Alvi, MBBS, ${ }^{1,2}$ Brett A. Freedman, MD, ${ }^{4}$ Benjamin D. Elder, MD, PhD, ${ }^{2}$ and \\ Mohamad Bydon, MD ${ }^{1,2}$
}

\begin{abstract}
${ }^{1}$ Mayo Clinic Neuro-Informatics Laboratory, Department of Neurologic Surgery, Mayo Clinic, Rochester; ${ }^{2}$ Department of Neurologic Surgery, Mayo Clinic, Rochester, Minnesota; ${ }^{2}$ Dr. Kiran C. Patel College of Allopathic Medicine, Nova Southeastern University, Davie, Florida; and ${ }^{4}$ Department of Orthopedic Surgery, Mayo Clinic, Rochester, Minnesota
\end{abstract}

\begin{abstract}
OBJECTIVE Platelet-rich plasma (PRP) is a biological agent obtained by centrifuging a sample of blood and retrieving a high concentration of platelets and plasma components. The concentrate is then stimulated for platelet secretion of various growth factors and cytokines. Although it is not widely used in clinical practice, its role in augmenting bony union among patients undergoing spinal fusion has been assessed in several clinical studies. The objective of this study was to perform a systematic review and meta-analysis of the existing literature to determine the efficacy of PRP use in spinal fusion procedures.
\end{abstract}

METHODS A comprehensive literature search was conducted using PubMed, Scopus, and EMBASE for studies from all available dates. From eligible studies, data regarding the fusion rate and method of assessing fusion, estimated blood loss (EBL), and baseline and final visual analog scale (VAS) scores were collected as the primary outcomes of interest. Patients were grouped by those undergoing spinal fusion with PRP and bone graft (PRP group) and those only with bone graft (graft-only group).

RESULTS The literature search resulted in 207 articles. Forty-five full-text articles were screened, of which 11 studies were included, resulting in a meta-analysis including 741 patients. Patients without PRP were more likely to have a successful fusion at the last follow-up compared with those with PRP in their bone grafts (OR 0.53, 95\% Cl 0.34-0.84; $p=$ 0.006). There was no statistically significant difference with regard to change in VAS scores $(O R 0.00,95 \% \mathrm{Cl}-2.84$ to 2.84; $p$ > 0.99) or change in EBL (OR 3.67, 95\% Cl-67.13-74.48; $p=0.92$ ) between the groups.

CONCLUSIONS This study found that the additional use of PRP was not associated with any significant improvement in patient-reported outcomes and was actually found to be associated with lower fusion rates compared with standard grafting techniques. Thus, PRP may have a limited role in augmenting spinal fusion.

https://thejns.org/doi/abs/10.3171/2020.3.SPINE2046

KEYWORDS PRP; platelet-rich plasma; bony union augmentation; autograft

$\mathrm{P}$ LATELET-RICH plasma (PRP) is a biological agent that is obtained by centrifuging a sample of typically autologous blood and retrieving a concentrate containing platelets and plasma components. ${ }^{1}$ PRP contains a plethora of growth factors and cytokines through the secretions of platelets. ${ }^{2,3}$ Factors expressed by PRP were found to be involved in the growth of mostly connective tissue-related structures, raising the hypothesis that it will help in growth and regeneration of connective tissue, potentially within the musculoskeletal system. Following the findings at the molecular level, PRP has been tested in various preclinical and translational studies for the treatment of musculoskeletal disorders and has shown a favorable potential. 4,5

Following clinical studies of PRP use in disorders such as osteoarthritis of the knee ${ }^{6}$ and plantar fasciitis, ${ }^{7}$ the first examples of PRP use in the spine were presented in the treatment of discogenic pain resulting from degenerative disc disease. ${ }^{8,9}$ Intradiscal PRP injections were found to be associated with significant reductions in back pain and

ABBREVIATIONS EBL = estimated blood loss; GRADE = Grading of Recommendations Assessment, Development and Evaluation; MD = mean difference; NOS = Newcastle-Ottawa Scale; PRP = platelet-rich plasma; RCT = randomized controlled trial; VAS = visual analog scale.

SUBMITTED January 10, 2020. ACCEPTED March 12, 2020.

INCLUDE WHEN CITING Published online May 22, 2020; DOI: 10.3171/2020.3.SPINE2046. 
increased rates of return to work. ${ }^{10}$ However, a considerable proportion of patients with degenerative disc disease undergo surgical procedures, and spinal fusions stand out as one of the most frequently utilized treatment modalities.

Stemming from the previous experience, several studies have since presented their findings after using PRP in addition to allografts in spinal fusion procedures. To date, there is variability in the conclusions regarding the benefit of PRP administration. In light of this ambiguity, we aimed to perform a systematic review and meta-analysis of the existing literature to determine the efficacy of PRP use in spinal fusion procedures.

\section{Methods}

The guidelines used for this systematic review and meta-analysis were the Preferred Reporting Items for Systematic Reviews and Meta-Analyses (PRISMA). ${ }^{11}$

\section{Search Strategy}

A comprehensive literature search was conducted using PubMed, Scopus, and EMBASE for studies from all available dates. Two independent investigators (W.W. and A.T.E.) conducted the search and selected the studies. In addition, references of included studies were reviewed to identify additional articles. The following keywords were used for the search: platelet rich plasma, artificial growth factors, lumbar fusion, and lumbar surgery.

\section{Selection Criteria}

Studies were included only if they 1) were randomized controlled trials (RCTs) or observational studies that compared outcomes between patients undergoing spinal fusion with the use of PRP and those without it, 2) recorded outcomes of interest, and 3) were written in the English language. Duplicate studies were only included if their patient populations were different.

\section{Data Extraction}

The following variables were abstracted from the included studies: 1) first author and year of publication; 2) study design; 3) comparative groups, 4) patient demographics, including age, sex, and average follow-up time; 5) fusion rate and method of assessing fusion; 6) estimated blood loss (EBL); 7) operative time; and 8) baseline and final visual analog scale (VAS), Oswestry Disability Index, and SF-36 scores.

The meta-analysis was conducted on 3 variables: fusion rate, VAS scores, and EBL. Due to inconsistent reporting across all studies, other outcomes could not undergo metaanalysis.

\section{Critical Appraisal}

The quality of studies was assessed using the Newcastle-Ottawa Scale (NOS) ${ }^{12}$ for observational studies and the Cochrane Collaboration's tool for assessing risk ${ }^{13}$ for RCTs. Confidence in the estimate of outcomes was assessed using the Grading of Recommendations Assessment, Development and Evaluation (GRADE) guidelines. ${ }^{14}$

\section{Statistical Analysis}

Categorical outcomes were summarized using odds ratios with 95\% confidence intervals. Mean differences (MDs) were used to summarize continuous outcomes. The two groups that were being compared were those undergoing spinal fusion with PRP and graft (PRP group) and those with a graft only (graft-only group). Heterogeneity was represented with the Higgins I-square $\left(\mathrm{I}^{2}\right)$. A randomeffects model was used when meta-analyses indicated greater than $50 \%$ heterogeneity. ${ }^{15}$ Pooled estimates and effect sizes were represented by forest plots, while funnel plots were used to indicate publication bias. Statistical analysis was conducted using Review Manager 5.3 (Cochrane Collaboration); $\mathrm{p}<0.05$ was considered significant.

\section{Results \\ Search Results}

Our literature search resulted in 207 articles. Forty-five full-text articles were screened, of which 11 studies were included for meta-analysis. Further information related to study selection is summarized in Fig. 1.

\section{Description of Studies}

Three articles were retrospective cohort studies, ${ }^{16-18}$ while 4 were nonrandomized, prospective studies ${ }^{19-23}$ and 4 were RCTs. ${ }^{24-27}$ A total of 741 patients were included in this meta-analysis, most of whom underwent posterolateral interbody fusion. A description of included studies can be found in Table 1 .

\section{Fusion Rate}

Ten studies, consisting of 691 patients, had available data to compare fusion rates between the two groups. Successful fusion at the last follow-up was seen in 249 (79.6\%) of 313 patients in the PRP group and 338 (89.4\%) of 378 patients in the graft group. Those without PRP were more likely to have a successful fusion than those with PRP in their bone grafts (OR 0.53, 95\% CI 0.34-0.84; $\mathrm{p}=$ 0.006) (Fig. 2).

\section{Visual Analog Scale}

Five studies reported VAS scores; 86 patients were included in the PRP group and 96 patients were included in graft-only group. There was no statistically significant difference in change in VAS scores between the groups (MD $0.00,95 \% \mathrm{CI}-2.84$ to 2.84 ; $\mathrm{p}>0.99$ ) (Fig. 3).

\section{Estimated Blood Loss}

Four studies recorded EBL (in mL), with 92 patients in the PRP group and 186 in the graft-only group. There was no statistically significant difference in change in EBL between the groups (MD 3.67, 95\% CI -67.13 to 74.48; $\mathrm{p}=$ 0.92) (Fig. 4).

\section{Quality of Included Studies and Bias Assessment}

Publication bias was not evident based on funnel plots as shown in Supplemental Figs. 1-3. Observational studies showed high quality based on the NOS for observational 


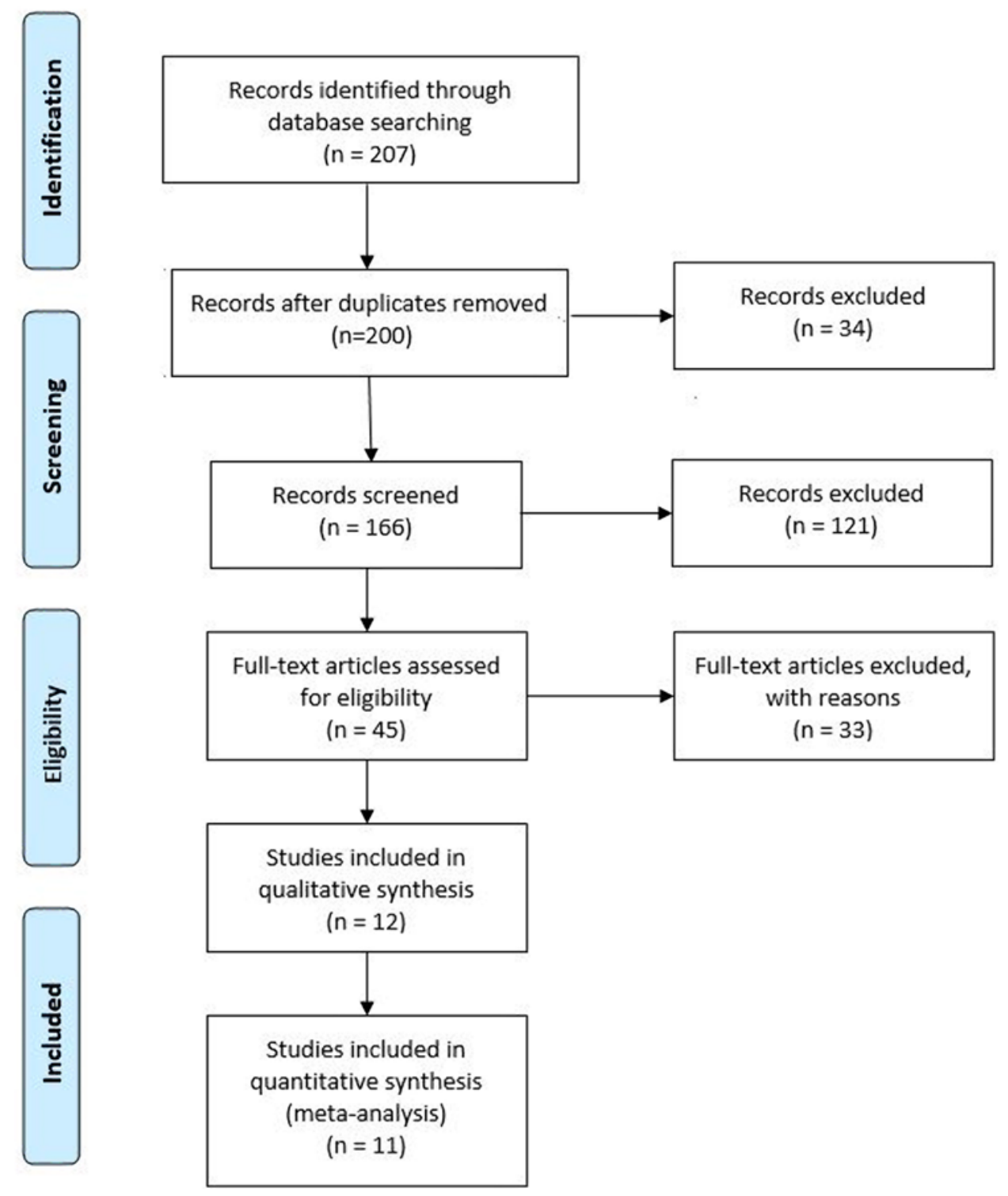

FIG. 1. PRISMA flowchart. Figure is available in color online only.

studies, where scores ranged from 5 to 8 of 8 . Three studies did not contain adequate selection of a nonexposed cohort; these studies selected their control groups through historical chart reviews. More details can be seen in Table 2. RCTs also showed high quality of study design based on the Cochrane tool for assessing risk, with scores ranging from 6 to 8 as shown in Supplemental Fig. 4.

GRADE assessment indicated moderate quality of outcome reporting for EBL and VAS, while fusion rate was reported to have high quality. More can be seen in Table 3 .

\section{Discussion}

This meta-analysis investigated the impact of PRP use on postsurgical outcomes for patients undergoing spinal fusion surgery. The results did not show any significant differences between PRP use and no PRP use with regard to VAS scores for pain (OR $0.00,95 \%$ CI -2.84 to 2.84; $\mathrm{p}>0.99$ ) and EBL (OR 3.67, 95\% CI -67.13 to $74.48 ; \mathrm{p}=$ $0.92)$. In terms of fusion rates, significantly higher rates were detected in patients who did not receive additional PRP compared with those in whom PRP was used (OR $0.53,95 \%$ CI $0.34-0.84 ; \mathrm{p}=0.006$ ).

Over the years, numerous additional products have been used to augment fusion and increase success in spinal fusion procedures. ${ }^{24}$ Currently, the most commonly utilized products are allografts, autografts, and bone morphogenetic protein. Allografts have been shown to be a promising material to supplement the fusion process in multiple studies ${ }^{28,29}$ However, allografts have been questioned in terms of efficacy and thought to have a lower success rate compared with autologous grafts. ${ }^{30}$ In contrast, autografts have been used as the gold standard for long periods of time, with "excellent" results following the fusion procedure. ${ }^{31,32}$ Still, autografts had their own safety concerns, namely the donor site-related complications (especially 


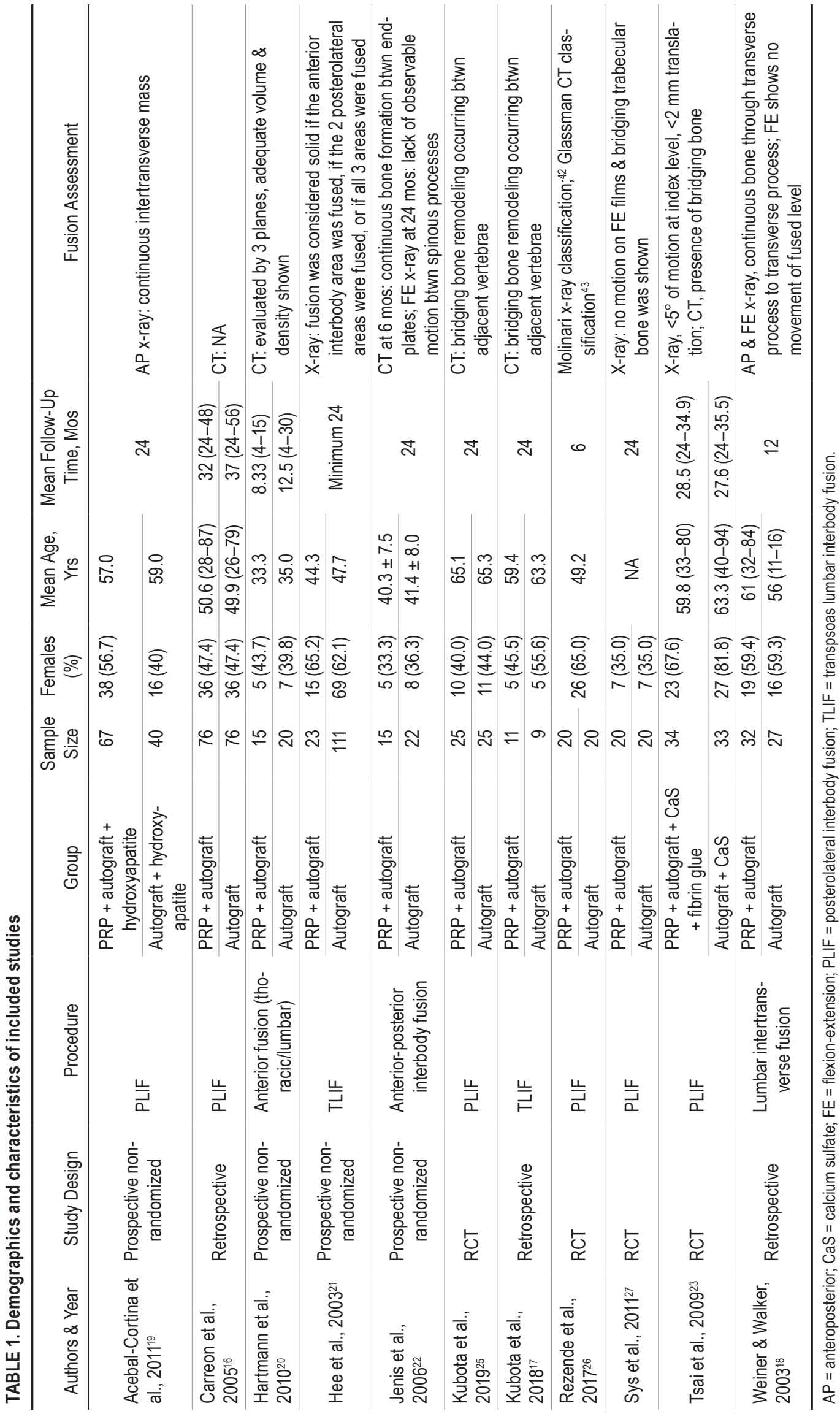




\begin{tabular}{|c|c|c|c|c|c|c|c|c|c|c|}
\hline \multirow[b]{2}{*}{ Study or Subgroup } & \multicolumn{2}{|c|}{ PRP + Graft } & \multicolumn{2}{|c|}{ Graft } & \multicolumn{3}{|c|}{ Odds Ratio } & \multirow{2}{*}{\multicolumn{3}{|c|}{$\begin{array}{c}\text { Odds Ratio } \\
\text { M-H, Fixed, } 95 \% \text { Cl }\end{array}$}} \\
\hline & Events & Total & Events & Total & Weight & M-H, Fixed, $95 \% \mathrm{Cl}$ & Year & & & \\
\hline Weiner and Walker, $2003^{18}$ & 17 & 32 & 24 & 27 & $23.3 \%$ & $0.14[0.04,0.57]$ & 2003 & & $\Rightarrow$ & \\
\hline Hee et al., $2003^{21}$ & 22 & 23 & 104 & 111 & $3.0 \%$ & $1.48[0.17,12.65]$ & 2003 & & & \\
\hline Carreon et al., $2005^{16}$ & 57 & 76 & 63 & 76 & $30.1 \%$ & $0.62[0.28,1.37]$ & 2005 & & & - \\
\hline Jenis et al., $2006^{22}$ & 13 & 15 & 19 & 22 & $3.9 \%$ & $1.03[0.15,7.02]$ & 2006 & & & \\
\hline Tsai et al., $2009^{23}$ & 29 & 34 & 30 & 33 & $8.6 \%$ & $0.58[0.13,2.65]$ & 2009 & & & \\
\hline Hartmann et al., $2010^{20}$ & 12 & 15 & 14 & 20 & $4.6 \%$ & $1.71[0.35,8.37]$ & 2009 & & & \\
\hline Acebal-Cortina et al., $2011^{19}$ & 50 & 67 & 37 & 40 & $22.5 \%$ & $0.24[0.07,0.87]$ & 2011 & & & \\
\hline Sys et al., $2011^{27}$ & 20 & 20 & 20 & 20 & & Not estimable & 2011 & & & \\
\hline Rezende et al., $2017^{26}$ & 19 & 20 & 20 & 20 & $2.8 \%$ & $0.32[0.01,8.26]$ & 2017 & & & \\
\hline Kubota et al., $2019^{25}$ & 10 & 11 & 7 & 9 & $1.3 \%$ & $2.86[0.21,37.99]$ & 2018 & & & \\
\hline Total $(95 \% \mathrm{Cl})$ & & 313 & & 378 & $100.0 \%$ & $0.53[0.34,0.84]$ & & & & \\
\hline Total events & 249 & & 338 & & & & & & & \\
\hline $\begin{array}{l}\text { Heterogeneity: } \mathrm{Chi}^{2}=10.25, \mathrm{~d} \\
\text { Test for overall effect: } \mathrm{Z}=2.74\end{array}$ & $\begin{array}{l}\text { If }=8(P= \\
(P=0.0\end{array}$ & $0.25)$ & $=22 \%$ & & & & & 0.01 & $\begin{array}{l}0.1 \\
\text { Favors [Graft] }\end{array}$ & $\begin{array}{c}10 \\
\text { Favors [PRP + Graft] }\end{array}$ \\
\hline
\end{tabular}

FIG. 2. Forest plot depicting ORs of the fusion rate. $M-H=$ Mantel-Haenszel. Figure is available in color online only.

with iliac crest bone graft), increased blood loss, and operative time. . $33,34^{-}$

To date, no specific guidelines have been put forward for selecting the number and choice of various grafts in different circumstances. Using both allograft and autograft is a common practice among spine surgeons. PRP has been recognized as a hybrid, having properties similar to both autografts and allografts. As an autologous product, it is similar to local bone grafts, or iliac crest bone graft, and its lack of a requirement for any secondary invasive procedures is similar to allografts. PRP is usually prepared first by separating red blood cells from whole blood, including plasma and platelets, by centrifugation. Then, it is centrifuged once more to extract more platelets and added to a specific plasma volume to produce a specific concentration. Additionally, different commer- cially available systems include proprietary products to the platelets, such as prepared leukocytes or citrate, to improve the concentration and effect of PRP. ${ }^{35}$ Although included studies have not reported significant complications, we did not detect any significant benefit of PRP in terms of patient-reported outcomes. This is a concerning finding since the use of an additional agent without any benefit may not be cost-efficient, but it only adds an average of $\$ 155$, according to Landi et al. ${ }^{36}$ However, it only adds an additional 18 minutes to transforaminal interbody fusions, on average.$^{37}$ Moreover, fusion rates were found to be better in the group without PRP use, further questioning its use in these cases. A recent systematic review by Elder et al. concluded that although PRP may be a promising strategy as a supportive agent in spinal fusion, there is insufficient evidence to recommend its use in spinal fu-

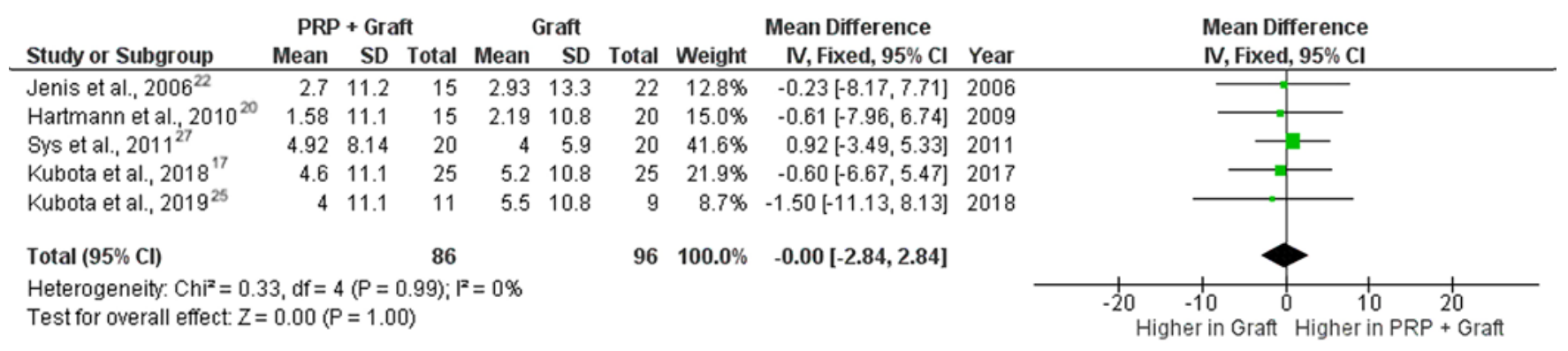

FIG. 3. Forest plot depicting MDs of change in VAS scores. Figure is available in color online only.

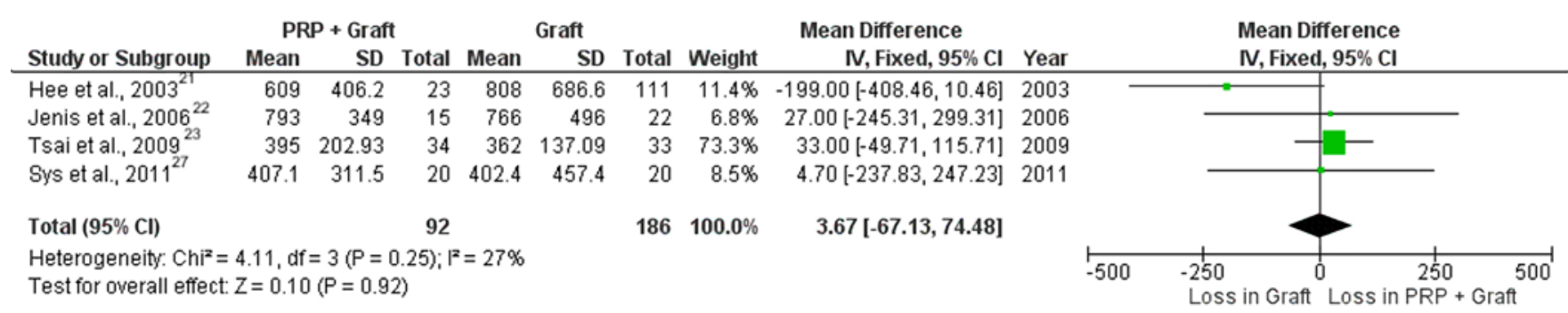

FIG. 4. Forest plot depicting MDs of EBL. Figure is available in color online only. 

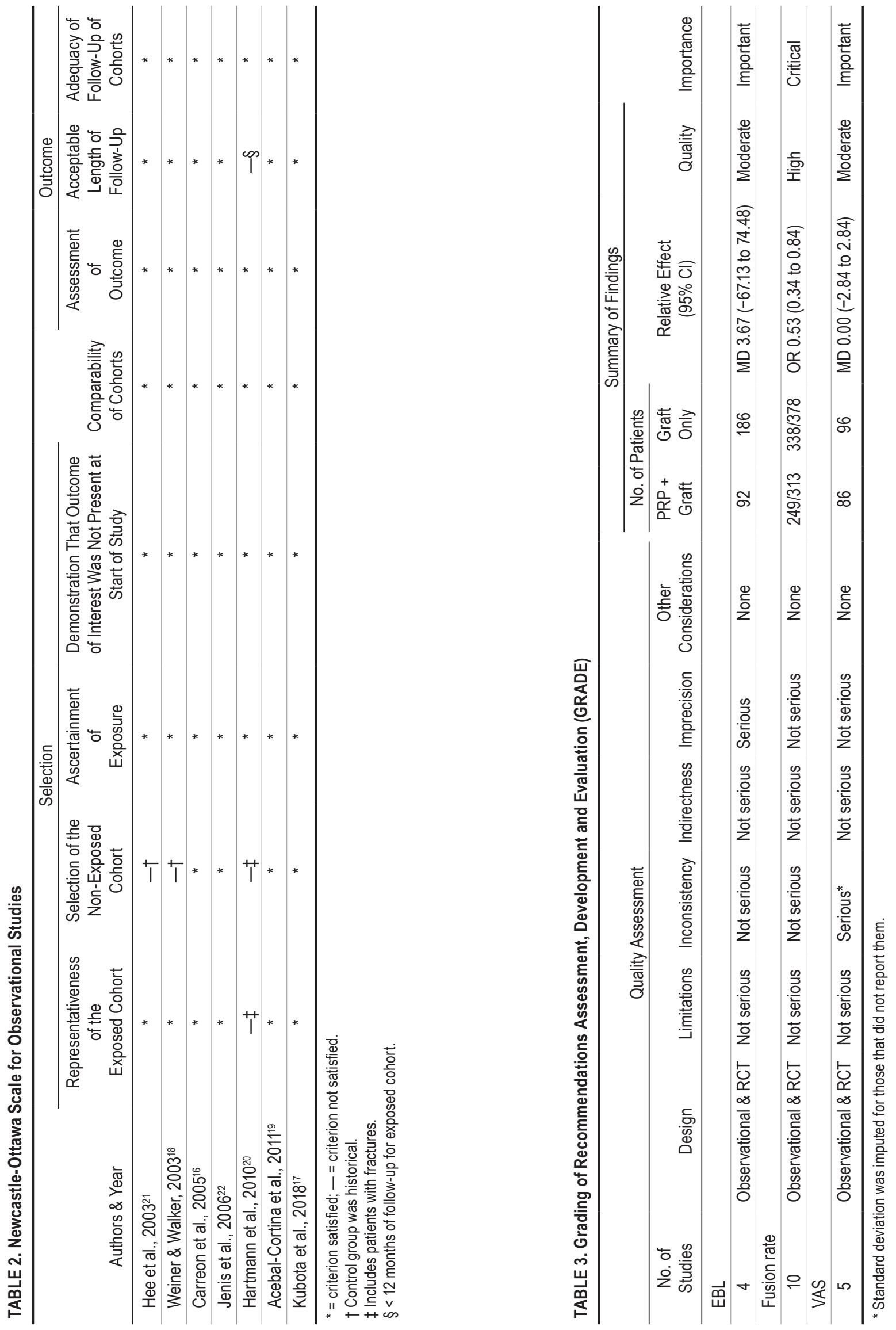
sion surgery. ${ }^{35}$ This idea was relatively due to the heterogeneity of studies and supports the statistical findings we obtained in the present study.

Stem cells are other potential agents that have been hypothesized to provide additional benefit in patients undergoing surgical procedures. ${ }^{38,39} \mathrm{~A}$ study by Eastlack et al. showed significant improvements in Neck Disability Index, neck VAS, arm VAS, SF-12 physical component, and SF-12 mental component scores with the use of stem cell allografts compared with cadaver allograft use in patients undergoing anterior cervical discectomy and fusion. ${ }^{40} \mathrm{~A}$ similar study was conducted for 61 patients undergoing extreme lateral interbody fusion in a single-arm prospective study, and a fusion rate of $90.2 \%$ was achieved at the end of the 1st-year follow-up. ${ }^{41}$ Taking the results of PRP studies into account, stem cells are reported to achieve better outcomes when compared with PRP use. Moreover, stem cells are suggested as replacements of allografts, while the use of PRP was mostly tested as a combination therapy with an autograft.

\section{Limitations}

This study has limitations. First, among 11 included studies, only 4 studies were RCTs with small variabilities in their study designs. However, funnel plots indicated minimal to no bias for nonrandomized studies, as shown in Supplemental Figs. 1-3. Second, although the majority of the procedures were posterior lumbar fusion procedures, inclusion of different approaches has a potential impact on the results. Based on the GRADE criteria in Table 3, however, our results show moderate to high impact. Third, included studies only covered lumbar fusions, which limits the generalizability of the findings to all spinal fusions. Fourth, the timing of fusion assessments was found to be heterogeneous among studies, but the follow-up times of 8 of 11 studies ranged from 24 to 32 months.

\section{Conclusions}

The present study evaluated the use of PRP as one of the alternative regenerative biological agents to promote bony union and improvement in patient-reported outcomes among patients undergoing spinal fusion. We found that the additional use of PRP is not associated with any significant improvement in patient-reported outcomes compared with the standard procedure and is associated with lower fusion rates. Therefore, PRP may have a limited role as a biological agent in spinal fusion.

\section{References}

1. Nguyen RT, Borg-Stein J, McInnis K. Applications of platelet-rich plasma in musculoskeletal and sports medicine: an evidence-based approach. PM R. 2011;3(3):226-250.

2. Molloy T, Wang Y, Murrell G. The roles of growth factors in tendon and ligament healing. Sports Med. 2003;33(5):381394.

3. Podd D. Platelet-rich plasma therapy: origins and applications investigated. JAAPA. 2012;25(6):44-49.

4. Akbulut S, Yagci A, Yay AH, Yalcin B. Experimental investigation of effects of platelet-rich plasma on early phases of orthodontic tooth movement. Am J Orthod Dentofacial Orthop. 2019;155(1):71-79.
5. Elghblawi E. Platelet-rich plasma, the ultimate secret for youthful skin elixir and hair growth triggering. J Cosmet Dermatol. 2018;17(3):423-430.

6. Wu Y-T, Hsu K-C, Li T-Y, et al. Effects of platelet-rich plasma on pain and muscle strength in patients with knee osteoarthritis. Am J Phys Med Rehabil. 2018;97(4):248-254.

7. Mahindra P, Yamin M, Selhi HS, et al. Chronic plantar fasciitis: effect of platelet-rich plasma, corticosteroid, and placebo. Orthopedics. 2016;39(2): e285-e289.

8. Levi D, Horn S, Tyszko S, et al. Intradiscal platelet-rich plasma injection for chronic discogenic low back pain: preliminary results from a prospective trial. Pain Med. 2016;17(6):1010-1022.

9. Monfett M, Harrison J, Boachie-Adjei K, Lutz G. Intradiscal platelet-rich plasma (PRP) injections for discogenic low back pain: an update. Int Orthop. 2016;40(6):1321-1328.

10. Lana J, Santana MHA, Belangero WD, Luzo A. Platelet-Rich Plasma. Regenerative Medicine: Sports Medicine, Orthopedic, and Recovery of Musculoskeletal Injuries. Springer; 2014.

11. Shamseer L, Moher D, Clarke M, et al. Preferred reporting items for systematic review and meta-analysis protocols (PRISMA-P) 2015: elaboration and explanation. $B M J$. 2015;350:g7647.

12. Wells GA, Shea B, O'Connell D, et al. The Newcastle-Ottawa Scale (NOS) for assessing the quality of nonrandomised studies in meta-analyses. Accessed April 2, 2020. http:// www.ohri.ca/programs/clinical_epidemiology/oxford.asp

13. Higgins JPT, Altman DG, Gøtzsche PC, et al. The Cochrane Collaboration's tool for assessing risk of bias in randomised trials. BMJ. 2011;343:d5928.

14. Atkins D, Best D, Briss PA, et al. Grading quality of evidence and strength of recommendations. BMJ. 2004;328(7454):1490.

15. Higgins JPT, Thompson SG, Deeks JJ, Altman DG. Measuring inconsistency in meta-analyses. $B M J$. 2003;327(7414):557-560.

16. Carreon LY, Glassman SD, Anekstein Y, Puno RM. Platelet gel (AGF) fails to increase fusion rates in instrumented posterolateral fusions. Spine (Phila Pa 1976). 2005;30(9):E243E247.

17. Kubota G, Kamoda H, Orita S, et al. Efficacy of platelet-rich plasma for bone fusion in transforaminal lumbar interbody fusion. Asian Spine J. 2018;12(1):112-118.

18. Weiner BK, Walker M. Efficacy of autologous growth factors in lumbar intertransverse fusions. Spine (Phila Pa 1976). 2003;28(17):1968-1971.

19. Acebal-Cortina G, Suárez-Suárez MA, García-Menéndez $\mathrm{C}$, et al. Evaluation of autologous platelet concentrate for intertransverse lumbar fusion. Eur Spine J. 2011;20(suppl 3):361-366.

20. Hartmann EK, Heintel T, Morrison RH, Weckbach A. Influence of platelet-rich plasma on the anterior fusion in spinal injuries: a qualitative and quantitative analysis using computer tomography. Arch Orthop Trauma Surg. 2010;130(7):909914.

21. Hee HT, Majd ME, Holt RT, Myers L. Do autologous growth factors enhance transforaminal lumbar interbody fusion? Eur Spine J. 2003;12(4):400-407.

22. Jenis LG, Banco RJ, Kwon B. A prospective study of Autologous Growth Factors (AGF) in lumbar interbody fusion. Spine J. 2006;6(1):14-20.

23. Tsai C-H, Hsu H-C, Chen Y-J, et al. Using the growth factors-enriched platelet glue in spinal fusion and its efficiency. J Spinal Disord Tech. 2009;22(4):246-250.

24. Buser Z, Brodke DS, Youssef JA, et al. Synthetic bone graft versus autograft or allograft for spinal fusion: a systematic review. J Neurosurg Spine. 2016;25(4):509-516.

25. Kubota G, Kamoda H, Orita S, et al. Platelet-rich plasma en- 
hances bone union in posterolateral lumbar fusion: a prospective randomized controlled trial. Spine J. 2019;19(2):e34-e40.

26. Rezende CF, Azevedo DP, Lourenço RB, et al. Evaluation of the effectiveness of platelet-rich plasma in the bone consolidation of patients submitted to lumbar arthrodesis. Rev Bras Ortop. 2017;52(6):693-698.

27. Sys J, Weyler J, Van Der Zijden T, et al. Platelet-rich plasma in mono-segmental posterior lumbar interbody fusion. Eur Spine J. 2011;20(10):1650-1657.

28. Huang D-G, Zhang X-L, Hao D-J, et al. Posterior atlantoaxial fusion with a screw-rod system: allograft versus iliac crest autograft. Clin Neurol Neurosurg. 2017;162:95-100.

29. Yson SC, Sembrano JN, Santos ERG. Comparison of allograft and polyetheretherketone (PEEK) cage subsidence rates in anterior cervical discectomy and fusion (ACDF). $J$ Clin Neurosci. 2017;38:118-121.

30. Tuchman A, Brodke DS, Youssef JA, et al. Iliac crest bone graft versus local autograft or allograft for lumbar spinal fusion: a systematic review. Global Spine J. 2016;6(6):592-606.

31. Ito Z, Imagama S, Kanemura T, et al. Bone union rate with autologous iliac bone versus local bone graft in posterior lumbar interbody fusion (PLIF): a multicenter study. Eur Spine J. 2013;22(5):1158-1163.

32. Sengupta DK, Truumees E, Patel CK, et al. Outcome of local bone versus autogenous iliac crest bone graft in the instrumented posterolateral fusion of the lumbar spine. Spine (Phila Pa 1976). 2006;31(9):985-991.

33. Keller EE, Triplett WW. Iliac bone grafting: review of 160 consecutive cases. J Oral Maxillofac Surg. 1987;45(1):11-14.

34. Summers BN, Eisenstein SM. Donor site pain from the ilium. A complication of lumbar spine fusion. J Bone Joint Surg Br. 1989;71(4):677-680.

35. Elder BD, Holmes C, Goodwin CR, et al. A systematic assessment of the use of platelet-rich plasma in spinal fusion. Ann Biomed Eng. 2015;43(5):1057-1070.

36. Landi A, Tarantino R, Marotta N, et al. The use of platelet gel in postero-lateral fusion: preliminary results in a series of 14 cases. Eur Spine J. 2011;20(1)(suppl 1):S61-S67.

37. Castro FPJ Jr. Role of activated growth factors in lumbar spinal fusions. J Spinal Disord Tech. 2004;17(5):380-384.

38. Hayashi T, Lord EL, Suzuki A, et al. A comparison of commercially available demineralized bone matrices with and without human mesenchymal stem cells in a rodent spinal fusion model. J Neurosurg Spine. 2016;25(1):133-137.

39. Liu Z, Zhu Y, Zhu H, et al. Enhancement of posterolateral lumbar spine fusion using recombinant human bone morphogenetic protein-2 and mesenchymal stem cells delivered in fibrin glue. J Biomater Appl. 2016;31(4):477-487.
40. Eastlack RK, Garfin SR, Brown CR, Meyer SC. Osteocel Plus cellular allograft in anterior cervical discectomy and fusion: evaluation of clinical and radiographic outcomes from a prospective multicenter study. Spine (Phila Pa 1976). 2014;39(22):E1331-E1337.

41. Tohmeh AG, Watson B, Tohmeh M, Zielinski XJ. Allograft cellular bone matrix in extreme lateral interbody fusion: preliminary radiographic and clinical outcomes. ScientificWorldJournal. 2012;2012:263637.

42. Molinari RW, Bridwell KH, Klepps SJ, Baldus C. Minimum 5-year follow-up of anterior column structural allografts in the thoracic and lumbar spine. Spine (Phila Pa 1976). 1999;24(10):967-972.

43. Glassman SD, Dimar JR, Carreon LY, et al. Initial fusion rates with recombinant human bone morphogenetic protein-2/compression resistant matrix and a hydroxyapatite and tricalcium phosphate/collagen carrier in posterolateral spinal fusion. Spine (Phila Pa 1976). 2005;30(15):1694-1698.

\section{Disclosures}

The authors report no conflict of interest concerning the materials or methods used in this study or the findings specified in this paper.

\section{Author Contributions}

Conception and design: Yolcu, Wahood, Eissa. Acquisition of data: Yolcu, Wahood, Eissa. Analysis and interpretation of data: Yolcu, Wahood, Alvi. Drafting the article: Yolcu, Wahood. Critically revising the article: all authors. Reviewed submitted version of manuscript: all authors. Approved the final version of the manuscript on behalf of all authors: Bydon. Statistical analysis: Yolcu, Wahood. Administrative/technical/material support: Bydon. Study supervision: Bydon.

\section{Supplemental Information Online-Only Content}

Supplemental material is available with the online version of the article.

Supplemental Figs. 1-4. https://thejns.org/doi/suppl/10.3171/ 2020.3.SPINE2046.

\section{Correspondence}

Mohamad Bydon: Mayo Clinic, Rochester, MN. bydon. mohamad@mayo.edu. 